\title{
Oxyresveratrol inhibits cellular tyrosinase-related oxidative stress-induced melanogenesis in B16 melanoma cells
}

\author{
Teerapat Rodboon ${ }^{1}$, Sarawoot Palipoch ${ }^{2}$, Seiji Okada ${ }^{3}$, Nisamanee Charoenchon ${ }^{1}$, Yaowarin Nakornpakdee ${ }^{1}$, \\ Prasit Suwannalert ${ }^{1 *}$ \\ ${ }^{1}$ Department of Pathobiology, Faculty of Science, Mahidol University, Bangkok 10400, Thailand. \\ ${ }^{2}$ School of Medicine, Walailak University, Nakhon Si Thammarat 80160, Thailand. \\ ${ }^{3}$ Division of Hematopoiesis, Joint Research Center for Human Retrovirus Infection and Graduate School of Medical Sciences, Kumamoto University, \\ Kumamoto, 860-0811, Japan.
}

\section{ARTICLE INFO \\ Received on: 03/05/2019 \\ Accepted on: 15/02/2020 \\ Available online: 04/04/2020}

Key words:

Oxyresveratrol, melanin,

oxidative stress, tyrosinase.

\begin{abstract}
Cellular oxidative stress is caused by an imbalance in the redox status and manifests as hyperpigmentation disorders. Reactive oxygen species, particularly hydrogen peroxide $\left(\mathrm{H}_{2} \mathrm{O}_{2}\right)$ as the highly reactive hydroxyl radicals, promote the melanin production through the induction of tyrosinase enzyme activity. In this study, the antioxidant activity of oxyresveratrol was investigated by 2,2'-azino-bis-3-ethylbenzothiazoline-6-sulfonic acid (ABTS) and 2,2-dipheny 1-1-picrylhydrazyl (DPPH) assays. In addition, melanin biosynthesis, tyrosinase activity, and cellular oxidants due to the bioactive component, oxyresveratrol, were determined in B16 cells by melanin content assay, cellular tyrosinase activity assay, and the dichloro-dihydro-fluorescein diacetate (DCFH-DA) assay, respectively. Hydrogen peroxide induced the melanogenesis through tyrosinase activity-related cellular oxidants, whereas oxyresveratrol showed a potent antioxidant activity by DPPH and ABTS assays. At the concentrations of 10 and $12.5 \mu \mathrm{g} / \mathrm{ml}$, oxyresveratrol significantly inhibited melanogenesis in B16 melanoma cells and also suppressed tyrosinase activity and cellular oxidants. Effective doses of oxyresveratrol inhibit melanogenesis through bioactivity of cellular tyrosinase-related oxidative stress.
\end{abstract}

\section{INTRODUCTION}

Cellular oxidative stress arising as a result of excessive free radicals or depletion of antioxidants is well recognized to cause cell damage (Golbidi et al., 2018). Melanocytes are specialized skin cells producing melanin pigments that act as antioxidants to minimize and neutralize free radicals, resulting in abnormal hyperpigmentation including actinic damage, age spots, and melasma (Cals-Grierson and Ormerod, 2004; Slominski et al., 2004). Free radicals are known to assist in the proliferation of melanocyte and the melanogenesis-related tyrosinase enzyme (Friedmann and Gilchrest, 1987; Mastore et al., 2005). Tyrosinase is a rate-limiting enzyme involved in melanin synthesis. Recently,

\section{"Corresponding Author}

Prasit Suwannalert, Department of Pathobiology, Faculty of Science, Mahidol University, Bangkok 10400, Thailand.E-mail: prasit.suw@ mahidol.ac.th an application of antioxidants has been proposed, which can reduce the melanocyte proliferation and melanogenesis by targeting on redox balance (Yamakoshi et al., 2003), since modulation of free radicals in melanin-producing cells has been shown to suppress melanin production through bioactivity of cellular tyrosinase-related oxidants.

Tetra-oxygenated stilbenes of oxyresveratrol found in white mulberry and Artocarpus lakoocha Roxb. (Kim et al., 2010; Maneechai et al., 2009) demonstrated the high antioxidant activity (Kim, 2007; Yokozawa and Kim, 2007), whereas the $\mathrm{OH}$ group of four-substituted resorcinol of oxyresveratrol was shown to be mostly related to tyrosinase inhibition (Kim and Uyama, 2005). Oxyresveratrol is an effective whitening agent in cosmetics. Hence, this active ingredient is potentially used to control hyperpigmentation disorders as pharmaceutical purposes. Therefore, the effects of oxyresveratrol on melanogenesis through bioactivities of cellular tyrosinase-related oxidative stress in B16 melanoma cells were investigated in this study. 


\section{MATERIALS AND METHODS}

\section{Oxyresveratrol sample}

OxyResvenox, the commercial standard of oxyresveratrol (Sabinsa Co. Ltd., Germany), was used as the oxyresveratrol sample. The sample solution was freshly prepared by dissolving in $40 \%$ ethanol solution and filtrating through $0.45-\mu \mathrm{m}$ polytetrafluoroethylene filter nylon. The sample was subsequently diluted with complete Dulbecco's Modified Eagle's Medium (DMEM) before using in the experiment.

\section{2,2'-Azino-bis (3-ethylbenzothiazoline-6-sulphonic acid) (ABTS) radical scavenging activity}

ABTS assay was performed according to the previous study (Shang et al., 2018). Briefly, various concentrations of the sample $(200 \mu \mathrm{l})$ or Trolox as a standard were separately mixed and allowed to react with freshly prepared ABTS working solution (1.8 $\mathrm{ml}$ ) for 30 minutes, and then, the absorbance was measured at 734 nm (Spectrophotometer Model UV-2650, Labomed, Los Angeles, CA). The scavenging activity was calculated and expressed as $\%$ ABTS radical scavenging activity by the following equation:

$\operatorname{ABTS}$ radical scavenging activity $(\%)=\left(\frac{\left(\mathrm{Abs}_{\text {control }}-\mathrm{Abs}_{\text {sample }}\right)}{\mathrm{Abs}_{\text {control }}}\right) \times 100$

where $\mathrm{Abs}_{\text {control }}$ was the absorbance of control and $\mathrm{Abs}_{\text {sample }}$ was the absorbance of sample at different concentrations. The assay was carried out in triplicate.

\section{2,2-Diphenyl-1-picrylhydrazyl (DPPH) radical scavenging activity}

DPPH radical scavenging activity was assayed by slightly modified method (Shang et al., 2018). Briefly, various concentrations of the sample $(200 \mu \mathrm{l})$ or Vitamin $\mathrm{C}$ standard were allowed to react with fresh DPPH working solution $(1.8 \mathrm{ml})$ for 30 minutes. The reaction was immediately measured at $540 \mathrm{~nm}$ by a spectrophotometer (UV-2650, Labomed, Angeles, CA). The scavenging activity was expressed as \% DPPH radical scavenging activity by following equation:

DPPH radical scavenging activity $(\%)=\left(\frac{\left(\mathrm{Abs}_{\text {control }}-\mathrm{Abs}_{\text {sample }}\right)}{\mathrm{Abs}_{\text {control }}}\right) \times 100$

where $\mathrm{Abs}_{\text {control }}$ was the absorbance of control and $\mathrm{Abs}_{\text {sample }}$ was the absorbance of sample at different concentrations. The assay was done in triplicate.

\section{B16 melanoma cells}

B16 melanoma cells (RIKEN Cell Bank, Tsukuba, Japan) were maintained in DMEM supplemented with $10 \%(\mathrm{v} / \mathrm{v})$ heat-inactivated fetal bovine serum, $100 \mathrm{U} / \mathrm{ml}$ of penicillin, 100 $\mathrm{mg} / \mathrm{ml}$ of streptomycin, and $3.7 \mathrm{mg} / \mathrm{ml}$ of $\mathrm{NaHCO}_{3}$ at $37^{\circ} \mathrm{C}$ with $5 \% \mathrm{CO}_{2}$.

\section{Oxyresveratrol on B16 cell viability}

B16 cell viability was investigated by MTT (3-(4,5-dimethylthiazol-2-yl)-2,5-diphenyltetrazolium bromide) assay as previously described by modification (Seo et al., 2018). Briefly, $3.0 \times 10^{4}$ cells of B16 were seeded in the 96-well microculture plates and cultured for 24 hours. The cultured medium was then discarded, and the cells were individually cultured with various concentrations of each sample in conditioned medium $(200 \mu \mathrm{l})$. After 24 hours of incubation, the cultured medium was substituted with $100 \mu \mathrm{l}$ of medium containing $10 \mu \mathrm{l}$ of $5 \mathrm{mg} / \mathrm{ml}$ MTT stock solution. The medium was discarded after additional incubation for 2 hours, and $100 \mu 1$ of absolute dimethyl sulfoxide was subsequently added to each well to solubilize the formazan crystal. The color was immediately read at a wavelength of $570 \mathrm{~nm}$. The result was expressed as a percentage of cell viability by comparing $100 \%$ of the untreated control.

\section{Melanin content}

The effect of oxyresveratrol on melanin biosynthesis was assayed using a modified method (Seo et al., 2018). In brief, $3.0 \times 10^{5}$ cells of B16 were seeded in 24-well plates and incubated in DMEM for 24 hours. The cells were pretreated with $50 \mathrm{nM}$ of $\alpha$-melanocyte-stimulating hormone ( $\alpha$-MSH) for 24 hours. The cells treated with $2 \mu \mathrm{M}$ of $\mathrm{H}_{2} \mathrm{O}_{2}$ for 1 hour were incubated in fresh DMEM for 6 hours to induce cellular oxidative stress. Oxidative stress-induced B16 cells were treated with 10 and $12.5 \mu \mathrm{g} / \mathrm{ml}$ of oxyresveratrol in DMEM or $50 \mathrm{mM}$ of sodium L-lactate (SLL), positive control, and incubated for 48 hours. To determine the melanin content, B16 cells were washed with phosphate-buffered saline (PBS) pH 7.4, lysed with $100 \mu 1$ of $1 \mathrm{~N} \mathrm{NaOH,} 1 \%$ Triton $\mathrm{X}-100$, and $1 \mathrm{mM}$ phenylmethylsulfonyl fluoride (PMSF), and incubated at $60^{\circ} \mathrm{C}$ for 1 hour. The lysate was optically measured at a wavelength of $405 \mathrm{~nm}$. The results were expressed as a percentage of melanogenesis, $100 \%$ for untreated cells.

\section{Fontana-Masson staining}

The melanin production and cellular morphology of B16 melanoma cells were stained with Fontana-Masson staining and obtained under microscopy (Vasilevska et al., 2016). In brief, 5.0 $\times 10^{5}$ cells of B16 were cultured in DMEM (6-well plates) for 24 hours. The cells were pretreated with $\alpha$-MSH $(50 \mathrm{nM})$ for 24 hours. The cells treated with $2 \mu \mathrm{M}$ of $\mathrm{H}_{2} \mathrm{O}_{2}$ for 1 hour were then incubated in fresh DMEM for 6 hours and incubated with DMEM containing oxyresveratrol or $50 \mathrm{mM}$ of SLL, positive control, for 48 hours. The cells were fixed with absolute ethanol and rehydrated with distilled water. Cells were subsequently incubated with an ammoniacal silver solution for 24 hours and gently rinsed with distilled water. Sodium thiosulfate solution was added for 5 minutes and counterstained with Mayer's Carmalum stain for 10 minutes. The melanin production and cellular morphology were obtained by a light microscopy (400× of magnification). Melaninproducing cells were calculated and expressed as a percentage of total cells (counted in 1,000 cells).

\section{Cellular tyrosinase activity}

Tyrosinase activity was evaluated by a modified method (Lin et al., 2011). B16 cells $\left(3.0 \times 10^{5}\right.$ cells $)$ were seeded in 24 -well plates and incubated for 24 hours. The cells were pretreated with $50 \mathrm{nM}$ of $\alpha$-MSH for 24 hours. Cells treated with 2 $\mu \mathrm{M}$ of $\mathrm{H}_{2} \mathrm{O}_{2}$ for 1 hour were incubated in fresh DMEM for 6 hours and then incubated with DMEM containing oxyresveratrol for 48 hours. The cells were then lysed by a freeze-thaw technique using lysing buffer (PBS, pH 6.8 containing $0.1 \%$ Triton X-100 and 0.1 $\mathrm{mM}$ PMSF). The lysate was clarified by centrifugation at 12,000 $\mathrm{g}, 4^{\circ} \mathrm{C}$ for 30 minutes. The $80 \mu \mathrm{l}$ of supernatant was transferred to 96 -well plates and incubated with $20 \mu \mathrm{l}$ of $20 \mathrm{mM}$ L-DOPA 
for 60 minutes. The reaction was detected at a wavelength of 492 $\mathrm{nm}$. The results were calculated and expressed as a percentage of tyrosinase activity (100\% for untreated cells). About $50 \mathrm{mM}$ of SLL was used as a positive control.

\section{Cellular oxidants}

Cellular oxidants were assayed by using a modified method (Aimvijarn et al., 2018). B16 cells $\left(3.0 \times 10^{5}\right.$ cells) were seeded in 96-well plates and incubated at $37^{\circ} \mathrm{C}, 5 \% \mathrm{CO}_{2}$ for 24 hours. The cells were pretreated with $50 \mathrm{nM}$ of $\alpha$-MSH for 24 hours. The cells treated with $2 \mu \mathrm{M}$ of $\mathrm{H}_{2} \mathrm{O}_{2}$ for 1 hours were incubated in fresh DMEM for 6 hours and then incubated with DMEM containing oxyresveratrol for 24 hours. Cultured media were subsequently replaced by $10 \mu \mathrm{M}$ of dichloro-dihydrofluorescein diacetate (DCFH-DA) in media and incubated at $37^{\circ} \mathrm{C}, 5 \% \mathrm{CO}_{2}$ for 1 hour.

Dichlorofluorescein (DCF) fluorescence was instantly evaluated for cellular oxidants using a fluorescence microplate reader (1420 Victor 2, Wallac, ID) at excitation/emission wavelengths of $485 / 535 \mathrm{~nm}$. N-acetyl cysteine at $5 \mathrm{mM}$ was used as a positive antioxidant. The results were expressed as $100 \%$ control for untreated cells.

\section{Statistical analysis}

Data were expressed as mean \pm standard deviation. The correlation was tested by the Pearson correlation test. The differences of means among comparative groups were determined by one-way analysis of variance (ANOVA) and independent t-test. Significant differences were considered at the level of $p \leq 0.05$.

\section{RESULTS AND DISCUSSION}

The generation of reactive oxygen species, especially $\mathrm{H}_{2} \mathrm{O}_{2}$, results in oxidative stress in epidermal melanocytes that promote the overproduction of melanin pigments (Panich et al., 2012). Here, we demonstrated that oxyresveratrol plays a crucial role in free radical scavenging activity in vitro examined by DPPH and ABTS assays at $28.735 \mathrm{mg} \pm 0.547 \mathrm{mg}$ Vit C/g sample and $2.312 \mathrm{mg} \pm 0.422 \mathrm{mg}$ Trolox/g sample, respectively. Both assays also showed gradually increasing antioxidant scavenging activities in a dose-dependent manner in Fig. 1. These results concurred with the previous studies that oxyresveratrol, a polyphenol in the family of stilbenes, is a free radical scavenger (Sun et al., 2010; Yokozawa and Kim, 2007).

Oxidative stress increases melanin production through tyrosinase enzyme pathway (Chang, 2009). In this study, we investigated noncytotoxic dose of oxyresveratrol to apply further in melanogenesis experiment. B16 cells treated with various doses of oxyresveratrol at $2.5,5.0,7.5,10$, and $12.5 \mu \mathrm{g} /$ $\mathrm{ml}$ did not impact on cell viability when compared with control (Fig. 2A). Interestingly, at doses 10 and $12.5 \mu \mathrm{g} / \mathrm{ml}$, oxyresveratrol suppressed melanogenesis significantly at $71 \% \pm 4.900 \%$ and $51 \% \pm 3.682 \%$, respectively, compared with $100 \%$ control
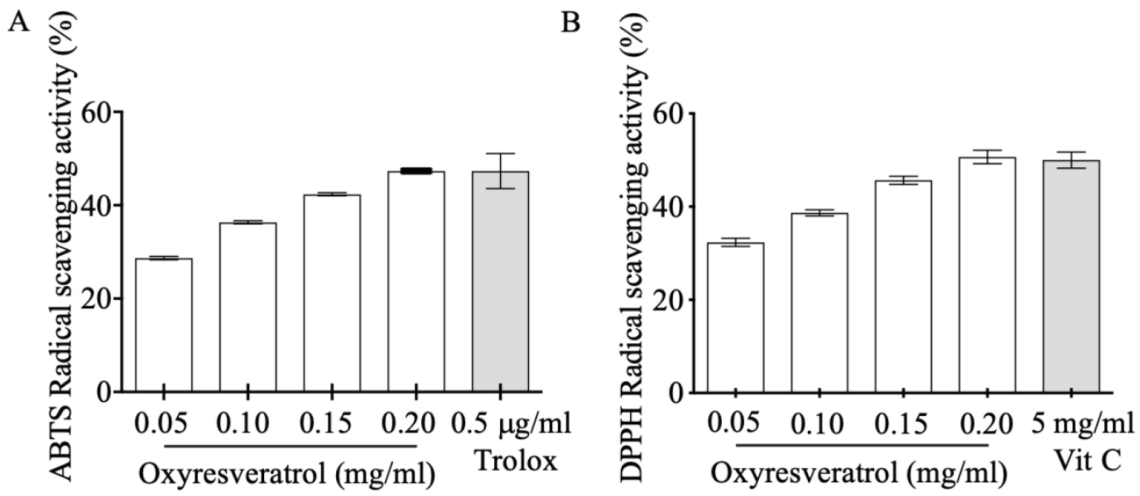

Figure 1. The antioxidant activity of oxyresveratrol by ABTS (A) and DPPH (B) assays. The results were expressed as mean $\pm \mathrm{SD}$.
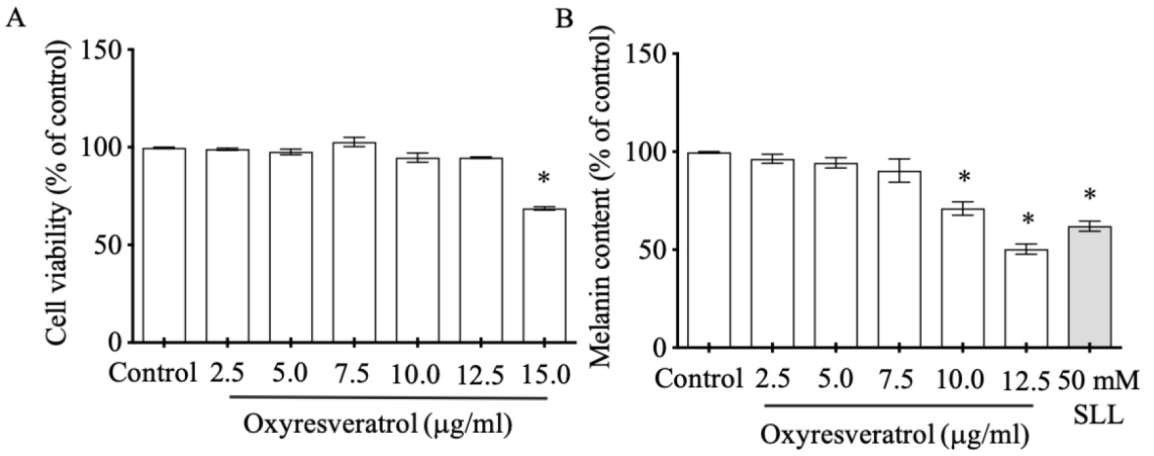

Figure 2. The effects of oxyresveratrol at various concentrations on B16 cell viability (A) and melanogenesis (B). SLL at $50 \mathrm{mM}$ was used as a melanogenesis inhibitor. The results were expressed as mean \pm SD. * Statistical significance between each treatment group and control at $p<0.001$. 
(Fig. 2B). These results were supported by the previous report that oxyresveratrol contained the moieties of 4-resorcinal and 5-resocinal, which act as a melanin inhibitor through tyrosinase function (Chang, 2009).

Hydrogen peroxide demonstrated the induction of both melanin content and tyrosinase activity. $\mathrm{H}_{2} \mathrm{O}_{2}$-induced oxidative stress enhanced melanogenesis at $140 \% \pm 5.933 \%(p<0.001)$ compared with control (Fig. 3A). We found that oxyresveratrol at the doses of 10 and $12.5 \mu \mathrm{g} / \mathrm{ml}$ showed melanogenesis inhibition in a dose-dependent manner at 39\% $\pm 8.419 \%(p<0.001)$ and $64 \%$ $\pm 10.536 \%(p<0.001)$, respectively, compared with the $\mathrm{H}_{2} \mathrm{O}_{2}-$ treated group. In addition, $\mathrm{H}_{2} \mathrm{O}_{2}(2 \mu \mathrm{M})$ also induced tyrosinase activity at $119 \% \pm 4.252 \%$ compared with control $(\mathrm{p}<0.001)$ as showed in Fig. 3B. Oxyresveratrol at the doses of 10 and $12.5 \mu \mathrm{g} /$ $\mathrm{ml}$ inhibited tyrosinase activity significantly in a dose-dependent manner $(p<0.001)$. The effect of oxyresveratrol on tyrosinase activity was greatly associated with melanogenesis $(r=0.948$, $p<0.05)$. These results concurred with the previous report that $\mathrm{H}_{2} \mathrm{O}_{2}$-induced oxidative stress induced the melanin production through the pathway of tyrosinase enzyme (Kim and Lee, 2013). Tyrosinase enzyme catalyzes the oxidation of 1-tyrosine and 1-3,4-dihydroxyphenylalanine (DOPA) to DOPA quinone, resulting in the formation of the brownish-black eumelanin. The excessive of eumelanin production is shown in hyperpigmentation (Khemis et al., 2007; Kim and Uyama, 2005). Interestingly, the phytopolyphenol compounds found in oxyresveratrol can inhibit tyrosinase-related melanogenesis through the antioxidant defense system and also inhibit melanogenesis associated with melanin production (Lorenz et al., 2003; Panich et al., 2012, Park et al., 2014). The cellular oxidants modulated by oxyresveratrol may thus play a crucial role in inhibiting melanogenesis through tyrosinase activity-related cellular oxidants. We also studied the effect of oxyresveratrol on cellular oxidants. Induction of cellular oxidants was achieved by the $2 \mu \mathrm{M} \mathrm{H}_{2} \mathrm{O}_{2}$-treated group at $173 \%$ $\pm 1.247 \%(p<0.001)$ when compared with the untreated group (100\% cellular oxidative stress). Oxyresveratrol treatment at the doses of 10 and $12.5 \mu \mathrm{g} / \mathrm{ml}$ showed a statistical significance in decreasing cellular oxidants in a dose-dependent manner at $87 \% \pm$ $2.055 \%(p<0.001)$ and $72 \% \pm 1.700 \%(p<0.001)$, respectively, compared with $\mathrm{H}_{2} \mathrm{O}_{2}$-induced $\mathrm{B} 16$ cells (Fig. 3C). The effect of oxyresveratrol on cellular oxidants was considerably associated with melanogenesis $(r=0.948, p<0.05)$ and tyrosinase activity $(r=0.965, p<0.05)$.

In addition, staining melanin pigments in B16 cells by the Fontana-Masson Stain Kit gave the percentage of melanin-containing cells at $45 \% \pm 4.497 \%$ in the control group (Fig. 4A), and it increased to $82 \% \pm 2.625 \%$ after treatment with 2 $\mu \mathrm{M}$ of $\mathrm{H}_{2} \mathrm{O}_{2}$ (Fig. 4B). Oxyresveratrol at the doses of 10 and 12.5 $\mu \mathrm{g} / \mathrm{ml}$ showed a significant suppression of melanin accumulation in a dose-dependent manner at $69 \% \pm 2.944 \%(p<0.05)$ (Fig. 4C) and $44 \% \pm 4.989 \%(p<0.001)$ (Fig. 4D), respectively, compared with the $\mathrm{H}_{2} \mathrm{O}_{2}$-treated group. Oxyresveratrol might be a potential candidate for further development of pharmaceutical products to combat antihyperpigmentary disorders.

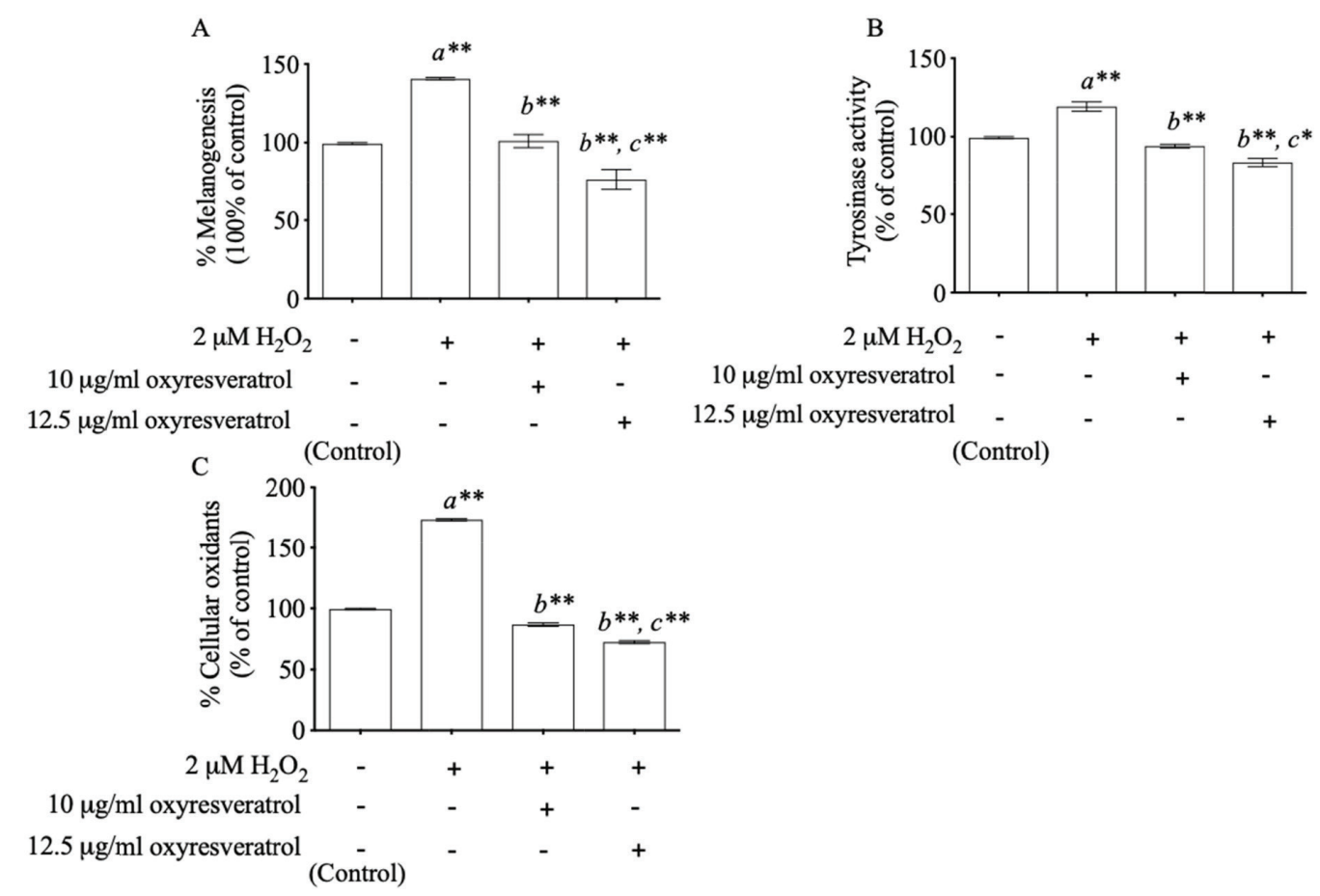

Figure 3. The effects of oxyresveratrol at the doses of 10 and $12.5 \mu \mathrm{g} / \mathrm{ml}$ on melanogenesis (A), tyrosinase activity (B), and cellular oxidants (C) in $\mathrm{H}_{2} \mathrm{O}_{2}$-induced $\mathrm{B} 16$ cells. The results were expressed as mean $\pm \mathrm{SD}$. ${ }^{*}$ and $* *$ represent the significant difference at $p<0.05$ and $p<0.001$ versus untreated group (a), $\mathrm{H}_{2} \mathrm{O}_{2}$-induced group (b), and $\mathrm{H}_{2} \mathrm{O}_{2}$-induced combined with $10 \mu \mathrm{g} / \mathrm{ml}$ oxyresveratrol-treated group (c), respectively. 


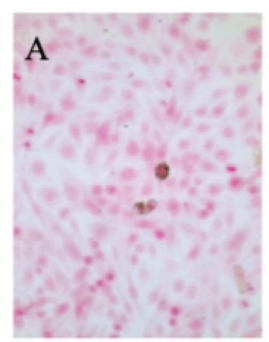

Control
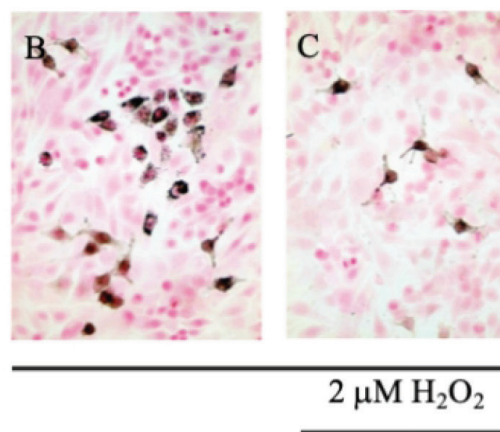

$10 \mu \mathrm{g} / \mathrm{ml}$
oxyresveratrol
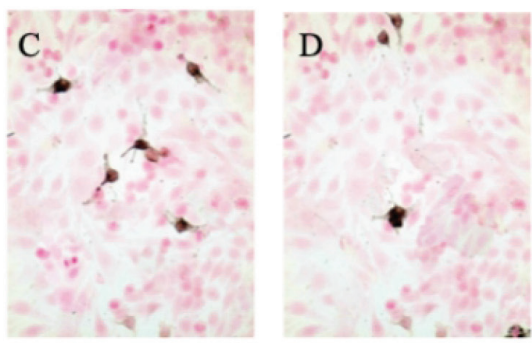

$12.5 \mu \mathrm{g} / \mathrm{ml}$ oxyresveratrol

$\mathrm{E} \stackrel{\oplus}{\bar{J}}$

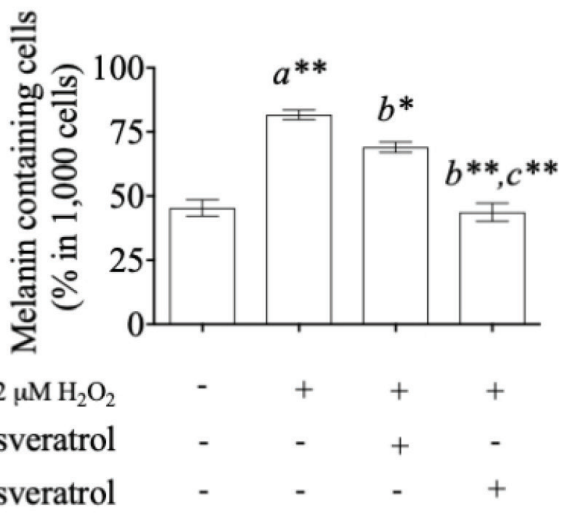

(Control)

Figure 4. The effect of oxyresveratrol at the doses of 10 and $12.5 \mu \mathrm{g} / \mathrm{ml}$ on melanin accumulation in $\mathrm{H}_{2} \mathrm{O}_{2}$-induced B16 cells. Fontana-Masson staining for melanin accumulation of untreated cells (A), $2 \mu \mathrm{M} \mathrm{H}_{2} \mathrm{O}_{2}$-induced B16 cells (B), $2 \mu \mathrm{M} \mathrm{H} 2 \mathrm{O} 2$ induction with $10 \mu \mathrm{g} / \mathrm{ml}$ (C), and $12.5 \mu \mathrm{g} / \mathrm{ml}$ (D) of oxyresveratrol. The percentages of melanin-containing cells were visualized by a light microscope at magnification $400 \times$, and all the results were expressed in graph with mean \pm SD (E). Statistical significance was evaluated by ANOVA test. * and ** represent the significant difference at $p<0.05$ and $p<0.001$ versus untreated group (a), $\mathrm{H}_{2} \mathrm{O}_{2}$-induced group (b), and $\mathrm{H}_{2} \mathrm{O}_{2}$-induced combined with $10 \mu \mathrm{g} / \mathrm{ml}$ oxyresveratrol-treated group (c), respectively.

\section{CONCLUSION}

$\mathrm{H}_{2} \mathrm{O}_{2}$-induced oxidative stress promoted a melanin production by inducing tyrosinase-related cellular oxidative stress. Oxyresveratrol was shown to inhibit melanogenesis through the bioactivity of tyrosinase-associated oxidative stress in B16 cells.

\section{ACKNOWLEDGMENTS}

This research was financially supported by the Department of Pathobiology, Faculty of Science, Mahidol University. The authors would like to thank Dr. Nasapon Povichit, Detox (Thailand) Co. Ltd., for providing standard oxyresveratrol.

\section{CONFLICT OF INTEREST}

No conflict of interest associated with this work.

\section{REFERENCES}

Aimvijarn P, Palipoch S, Okada S, Suwannalert P. Thai water lily extract induces B16 melanoma cell apoptosis and inhibits cellular invasion through the role of cellular oxidants. Asian Pac J Cancer Prev, 2018; 19:149-53.

Cals-Grierson MM, Ormerod AD. Nitric oxide function in the skin. Nitric Oxide, 2004; 10:179-93.
Chang TS. An updated review of tyrosinase inhibitors. Int J Mol Sci, 2009; 10:2440-75.

Friedmann PS, Gilchrest BA. Ultraviolet radiation directly induces pigment production by cultured human melanocytes. J Cell Physiol, 1987; 133:88-94.

Golbidi S, Li H, Laher I. Oxidative stress: a unifying mechanism for cell damage induced by noise, (water-pipe) smoking, and emotional stress-therapeutic strategies targeting redox imbalance. Antioxid Redox Signal, 2018; 28:741-59.

Khemis A, Kaiafa A, Queille-Roussel C, Duteil L, Ortonne JP Evaluation of efficacy and safety of rucinol serum in patients with melasma: a randomized controlled trial. Br J Dermatol, 2007; 156:997-1004.

Kim HE, Lee SG. Induction of ATP synthase $\beta$ by $\mathrm{H}_{2} \mathrm{O}_{2}$ induces melanogenesis by activating PAH and cAMP/CREB/MITF signaling in melanoma cells. Int J Biochem Cell Biol, 2013; 45:1217-22.

Kim JK, Kim M, Cho SG, Kim MK, Kim SW, Lim YH. Biotransformation of mulberroside A from Morus alba results in enhancement of tyrosinase inhibition. J Ind Microbiol Biotechnol, 2010; $37: 631-7$.

Kim YJ, Uyama H. Tyrosinase inhibitors from natural and synthetic sources: structure, inhibition mechanism and perspective for the future. Cell Mol Life Sci, 2005; 62:1707-23.

Kim YJ. Antimelanogenic and antioxidant properties of gallic acid. Biol Pharm Bull, 2007; 30:1052-5. 
Lin CH, Ding HY, Kuo SY, Chin LW, Wu JY, Chang TS. Evaluation of in vitro and in vivo depigmenting activity of raspberry ketone from Rheum officinale. Int J Mol Sci, 2011; 12:4819-35.

Lorenz P, Roychowdhury S, Engelmann M, Wolf G, Horn TF. Oxyresveratrol and resveratrol are potent antioxidants and free radical scavengers: effect on nitrosative and oxidative stress derived from microglial cells. Nitric Oxide, 2003; 9:64-76.

Maneechai S, Likhitwitayawuid K, Sritularak B, Palanuvej C, Ruangrungsi N, Sirisa-Ard P. Quantitative analysis of oxyresveratrol content in Artocarpus lakoocha and "Puag-Haad". Med Princ Pract, 2009; 18:223-7.

Mastore M, Kohler L, Nappi AJ. Production and utilization of hydrogen peroxide associated with melanogenesis and tyrosinase-mediated oxidations of DOPA and dopamine. FEBS J, 2005; 272:2407-15.

Panich U, Onkoksoong T, Limsaengurai S, Akarasereenont P, Wongkajornsilp A. UVA-induced melanogenesis and modulation of glutathione redox system in different melanoma cell lines: the protective effect of gallic acid. J Photochem Photobiol B, 2012; 108:16-22.

Park J, Park, JH, Suh HJ, Lee IC, Koh J, Boo YC. Effects of resveratrol, oxyresveratrol, and their acetylated derivatives on cellular melanogenesis. Arch Dermatol Res, 2014; 306:475-87.

Seo JO, Yumnam S, Jeong KW, Kim SY. Finasteride inhibits melanogenesis through regulation of the adenylate cyclase in melanocytes and melanoma cells. Arch Pharm Res, 2018; 41:324-32.

Shang HM, Zhou HZ, Yang JY, Li R, Song H, Wu HX. In vitro and in vivo antioxidant activities of inulin. PLoS One, 2018; 13:e192273.

Slominski A, Tobin DJ, Shibahara S, Wortsman J. Melanin pigmentation in mammalian skin and its hormonal regulation. Physiol Rev, 2004; 84:1155-228.
Sun HY, Xiao CF, Cai YC, Chen Y, Wei W, Liu XK, Lv ZL, Zou Y. Efficient synthesis of natural polyphenolic stilbenes: resveratrol, piceatannol and oxyresveratrol. Chem Pharm Bull (Tokyo), 2010; 58 $1492-6$.

Vasilevska J, De Souza GA, Stensland M, Skrastina D, Zhulenvovs D, Paplausks R, Kurena B, Kozlovska T, Zajakina A. Comparative protein profiling of B16 mouse melanoma cells susceptible and non-susceptible to alphavirus infection: Effect of the tumor microenvironment. Cancer Biol Ther, 2016; 17:1035-50.

Yamakoshi J, Otsuka F, Sano A, Tokutake S, Saito M, Kikuchi M, Kubota Y. Lightening effect on ultraviolet-induced pigmentation of guinea pig skin by oral administration of a proanthocyanidin-rich extract from grape seeds. Pigment Cell Res, 2003; 16:629-38.

Yokozawa T, Kim YJ. Piceatannol inhibits melanogenesis by its antioxidative actions. Biol Pharm Bull, 2007; 30:2007-11.

How to cite this article:

Rodboon T, Palipoch S, Okada S, Charoenchon N, Nakornpakdee Y, Suwannalert P. Oxyresveratrol inhibits cellular tyrosinase-related oxidative stress-induced melanogenesis in B16 melanoma cells. J Appl Pharm Sci, 2020; 10(04):008-013. 